\title{
Defining and measuring health literacy: what can we learn from literacy studies?
}

\author{
Don Nutbeam
}

Published online: 30 July 2009

(C) Birkhäuser Verlag, Basel/Switzerland 2009

Previous contributions to this series of editorials and other recent papers have highlighted the growth in interest in health literacy, as well as continuing debate about its definition, measurement and importance (Kickbusch 2009; Wills 2009; Abel 2008; Nutbeam 2008; Coulter and Ellins 2007). In further advancing these debates there is much to be gained from an appraisal of the underlying concept of literacy.

Literacy is an important but complex concept. Generally it is acknowledged as having two distinctive elements: those that are task-based, and those that are skill-based (National Assessment of Adult Literacy 2003). Task-based literacy focuses on the extent to which a person can perform key literacy tasks such as read a basic text and write a simple statement. Skill-based literacy focuses on the knowledge and skills an adult must possess in order to perform these tasks. These skills range from basic, wordlevel skills (such as recognising words) to higher level skills (such as drawing appropriate inferences from continuous text).

It follows that literacy can be measured in absolute terms by distinguishing between those who can read and write basic text and those who cannot, and in relative terms

Don Nutbeam is currently Vice-Chancellor of the University of Southampton (UK) having spent much of the past 20 years at the University of Sydney, Australia. For the period 2000-2003, he was Head of Public Health in the UK (Blair) government Department of Health. His research interests have included public health intervention research in schools and communities as well as studies of health literacy, and adolescent health behaviour.

D. Nutbeam $(\bowtie)$

Office of the Vice-Chancellor, University of Southampton, University Road, Southampton SO17 1BJ, UK

e-mail: d.nutbeam@soton.ac.uk by assessing the skill differences between adults who are able to perform relatively challenging literacy tasks and those who are not.

The reason why we care so much about literacy is that even the most basic functional literacy skills enable people to better develop their knowledge and improve the potential to achieve personal goals, and through this to participate more fully in society, both economically and socially. Given this background, it is not surprising to find that literacy levels in a population are associated both directly and indirectly with a range of health outcomes. Low literacy is often linked to poor socio-economic circumstances, and in turn with adverse effects on health that are independent of other risk factors (Jahan 2008). This is especially the case in the relationship between female literacy and maternal and child health outcomes (Schell et al. 2007). People with poor literacy tend to be less responsive to health education, less likely to use disease prevention services, and to successfully manage chronic disease (Dewalt et al. 2004).

Responding to low levels of literacy in a population involves improving access to effective school education, and providing adult literacy programs for those in need. Achieving high levels of literacy in a population is not only a vital development goal, but will also produce substantial public health benefits.

To better understand health literacy as a distinct concept, it is helpful to delve into current discourse on different "literacies", recognising that literacy is both content and context specific. This is especially the case in relation to "new literacies" emerging in response to new information technologies (Coiro 2003), and context-specific literacies such as media literacy and financial literacy (Primack and Hobbs 2009; Kozup and Hogarth 2008). This further refinement in the concept reflects the fact that individuals 
with higher levels of general literacy (task- and skill-based) may not be able to consistently apply their knowledge and skills in situations requiring specific content knowledge, or in unfamiliar contexts; such as in relation to health knowledge, or a health care environment.

To some extent, the concept of health literacy can be seen as emerging from a growing awareness of content-specific literacy in a health context. This has led to examination of the relationship between low literacy and a range of health conditions, as well as progressive testing of interventions designed to mitigate the effects of low literacy through modified communications, and improved service organization (Pignone et al. 2005). Much of the scientific enquiry into "health literacy" emanating from the US is, in fact, focused on ways in which health care providers and the health system could better identify, manage and respond to the needs of patients with low literacy, and those with poor content and context literacy in a health environment. This continues to be important and valuable work, but would be more appropriately described as responding to what Baker refers to as "health-related literacy" in clinical settings (Baker 2006).

To find a more complete conceptualisation of health literacy requires us to bring together a sophisticated understanding of literacy with distinctive health content and contexts. In this sense, health literacy is the ability to perform knowledge-based literacy tasks and the possession of literacy skills that are required in different health contexts. The commonly used definitions of health literacy as the capacity to acquire, understand and use information in ways which promote and maintain good health remain valid (Nutbeam 1998; Institute of Medicine 2004), but can be more fully understood with an appreciation of key literacy concepts.

It follows that (as with other "literacies") health literacy can be developed through education. Health literacy can be regarded as a measurable outcome to health education in the same way that measures of literacy are used as one way of assessing the success of school education. Furthermore, it follows that the measurement of health literacy will be best achieved where content and context are well defined; health literacy will be different for a person with diabetes who is receiving patient education, compared with a pregnant woman attending ante-natal classes, or a young person exposed to health education at school.

Similar to literacy, health literacy can be measured at different levels, corresponding to higher level "health literacy" skills that relate to the acquisition, understanding and application of context-specific knowledge. As in general literacy studies, these levels can be described as functional, interactive and critical health literacy (Nutbeam 2000). The different levels are distinguished by the higher levels of knowledge and skills that progressively support greater autonomy and personal empowerment in health- related decision-making, as well as engagement with a wider range of health knowledge that extends from personal health management to the social determinants of health. These skills can be developed both through formal health education and other less formal exposure to health knowledge and practices.

Current widely used measures of health literacy such as TOFLA and REALM (Parker et al. 1995; Davis et al. 1993) are useful screening tools in clinical environments, but not comprehensive measures of health literacy; measuring only selective domains that are thought to be markers of an individual's overall capacity (Baker 2006). The more recent US Health Activity Literacy Scale (HALS) is a more comprehensive test, as it differentiates between healthrelated competencies in five domains (health promotion, health protection, disease prevention, health care and maintenance, and systems navigation), and between different health literacy tasks and skills (Educational Testing Service 2006; Rudd 2007).

The work in the US on HALS as well as in other countries including Canada, Australia and Switzerland (Canadian Council on Learning 2008; Australian Bureau of Statistics 2006; Wang and Schmid 2006) represents good progress in measurement. Much work remains to be done to develop indices that are tailored to defined health content and contexts, and that distinguish between the different levels of knowledge and skills that reflect functional, interactive and critical health literacy. It is highly likely that different measurement tools will be required for different ages and stages in life (Renkert and Nutbeam 2001), even if the structure of the concept remains constant.

\section{References}

Abel T (2008) Measuring health literacy: moving towards a health promotion perspective. Int J Public Health 53:169-170

Australian Bureau of Statistics (2006) Health Literacy Australia. Australian Bureau of Statistics. http://www.ausstats.abs.gov.au/ ausstats/subscriber.nsf/0/73ED158C6B14BB5ECA2574720011 AB83/\$File/42330_2006.pdf. Accessed 18 May 2009

Baker DW (2006) The meaning and measure of health literacy. J Gen Intern Med 21:878-883

Canadian Council on Learning (2008) Health literacy in Canada: a healthy understanding. http://www.ccl-cca.ca/NR/rdonlyres/ 266E0889-8B9B-45DB-B615-33E146E31B06/0/HealthLiteracy ReportFeb2008E.pdf. Accessed 18 May 2009

Coiro J (2003) Exploring literacy on the internet-reading comprehension on the internet: expanding our understanding of reading comprehension to encompass new literacies. Read Teach 56:458-464

Coulter A, Ellins J (2007) Effectiveness of strategies for informing, educating and involving patients. BMJ 335:24-26

Davis TC, Long SW, Jackson RH et al (1993) Rapid estimate of literacy in medicine: a shortened screening instrument. Fam Med 25:391-395 
Dewalt DA, Berkman ND, Sheridan S et al (2004) Literacy and health outcomes: a systematic review of the literature. J Gen Intern Med 19:128-139

Educational Testing Service (2006) Test content for health activities literacy tests. ETS Princeton, New Jersey. http://www.ets.org/. Accessed 18 May 2009

Institute of Medicine (2004) Health literacy: a prescription to end confusion. National Academies Press, Washington, DC

Jahan S (2008) Poverty and infant mortality in the Eastern Mediterranean region: a meta-analysis. J Epidemiol Community Health 62:745-751

Kickbusch I (2009) Health literacy: engaging in a political debate. Int J Public Health 54:131-132

Kozup J, Hogarth JM (2008) Financial literacy, public policy, and consumers self-protection-more questions, fewer answers. J Consum Aff 42:127-136

National Assessment of Adult Literacy (2003) Definition of literacy. http://nces.ed.gov/NAAl/fr_definition.asp. Accessed 18 May 2009

Nutbeam D (1998) Health promotion glossary. Health Prom Int 13:349-364 See also: http://www.who.int/hpr/NPH/docs/hp_ glossary_en.pdf. Accessed 18 May 2009

Nutbeam D (2000) Health literacy as a public health goal: a challenge for contemporary health education and communication strategies into the 21st century. Health Prom Int 15:259-267

Nutbeam D (2008) The evolving concept of health literacy. Soc Sci Med 67:272-278
Parker RM, Baker DW, Williams MV et al (1995) The test of functional health literacy in adults (TOFLA): a new instrument for measuring patient's literacy skills. J Gen Intern Med 10:537542

Pignone M, DeWalt D, Sheridan S et al (2005) Interventions to improve health outcomes for patients with low literacy. J Gen Intern Med 20:185-192

Primack BA, Hobbs R (2009) Association of various components of media literacy and adolescent smoking. Am J Health Behav Am 33:192-201

Renkert S, Nutbeam D (2001) Opportunities to improve maternal health literacy through ante-natal education: an exploratory study. Health Prom Int 16:381-388

Rudd RE (2007) Health literacy skills of US adults. Am J Health Behav 31:S8-S18

Schell CO, Reilly M, Rosling $\mathrm{H}$ et al (2007) Socioeconomic determinants of infant mortality: a worldwide study of 152 low, middle and high-income countries. Scand J Public Health 35:288-297

Wang J, Schmid M (2006) Regional differences in health literacy in Switzerland. University of Zurich, Institute for Social and Preventive Medicine. http://www.futurepatient.ch/UserFiles/File/ Hintergrund\%20Gesundheitskompetenz_en_070607.pdf?future patient $=54$ fced $9548370 \mathrm{fcbffa} 1 \mathrm{~d} 5099 \mathrm{be} 10041$. Accessed 18 May 2009

Wills J (2009) Health literacy: new packaging for health education or a radical movement? Int J Public Health 54:3-4 